Published in final edited form as:

Cochrane Database Syst Rev. ; (3): CD007550. doi:10.1002/14651858.CD007550.pub2.

\title{
Single dose oral dexibuprofen [S(+)-ibuprofen] for acute postoperative pain in adults
}

\author{
R Andrew Moore ${ }^{1}$, Sheena Derry ${ }^{1}$, and Henry J McQuay ${ }^{1}$ \\ ${ }^{1}$ Pain Research and Nuffield Department of Anaesthetics, University of Oxford, Oxford, UK
}

\begin{abstract}
Background-Dexibuprofen ( $\mathrm{S}(+)$-ibuprofen) is a non-steroidal anti-inflammatory drug (NSAID) licensed for use in rheumatic disease and other musculoskeletal disorders in the UK, and widely available in other countries worldwide. It is an active isomer of ibuprofen. This review sought to evaluate the efficacy and safety of oral dexibuprofen in acute postoperative pain, using clinical studies of patients with established pain, and with outcomes measured primarily over 6 hours using standard methods. This type of study has been used for many decades to establish that drugs have analgesic properties.
\end{abstract}

Objectives-To assess efficacy, duration of action, and associated adverse events of single dose oral dexibuprofen in acute postoperative pain in adults.

Search methods-We searched Cochrane CENTRAL, MEDLINE, EMBASE and the Oxford Pain Relief Database for studies to May 2009.

Selection criteria-Randomised, double blind, placebo-controlled clinical trials of oral dexibuprofen for relief of acute postoperative pain in adults.

Data collection and analysis-Two review authors independently assessed trial quality and extracted data. Pain relief or pain intensity data were extracted and converted into the dichotomous outcome of number of participants with at least 50\% pain relief over 4 to 6 hours, from which relative risk and number needed to treat to benefit (NNT) were calculated. Numbers of participants using rescue medication over specified time periods, and time to use of rescue medication, were sought as additional measures of efficacy. Information on adverse events and withdrawals were collected.

Copyright $\odot 2010$ The Cochrane Collaboration. Published by John Wiley \& Sons, Ltd.

Contact address: Maura Moore, Pain Research and Nuffield Department of Anaesthetics, University of Oxford, West Wing (Level 6), John Radcliffe Hospital, Oxford, Oxfordshire, OX3 9DU, UK. maura.moore @ pru.ox.ac.uk.

CONTRIBUTIONS OF AUTHORS SD and RAM performed searching, data extraction, and analysis, including assessment of study quality. HJM helped with analysis and acted as arbitrator. All review authors contributed to writing. SD will be responsible for updating the review.

Editorial group: Cochrane Pain, Palliative and Supportive Care Group.

Publication status and date: Stable (no update expected for reasons given in 'What's new'), published in Issue 12, 2010.

Review content assessed as up-to-date: 9 November 2010.

DECLARATIONS OF INTEREST SD, RAM \& HJM have received research support from charities, government and industry sources at various times. This work was supported by an NHS Cochrane Collaboration Grant and NIHR Biomedical Research Centre Programme. RAM and HJM have consulted for various pharmaceutical companies. RAM and HJM have received lecture fees from pharmaceutical companies related to analgesics and other healthcare interventions.

NOTES The authors declare that there is unlikely to be any further studies to be included in this review and so it should be published as a 'stable review'. 
Main results-In the single included study, both $\mathrm{S}(+)$-ibuprofen (dexibuprofen, an active isomer of ibuprofen) $200 \mathrm{mg}$ and $400 \mathrm{mg}$ gave high levels of response, with 31/51 (61\%) and 35/50 (70\%) respectively having at least 50\% pain relief over 4 to 6 hours, compared with $2 / 25(8 \%)$ with placebo. The median time to additional analgesic use was 5.8 hours, 6.1 hours, and 1.8 hours respectively. The numbers of participants was too small to calculate NNTs with any meaning.

Authors' conclusions-The information from the single trial in acute postoperative pain suggests it to be a useful analgesic, but at doses not very different from racemic ibuprofen.

\section{Medical Subject Headings (MeSH)}

Acute Disease; Administration, Oral; Analgesics, Non-Narcotic [*administration \& dosage]; AntiInflammatory Agents, Non-Steroidal [*administration \& dosage]; Ibuprofen [administration \& dosage; *analogs \& derivatives]; Pain, Postoperative [*drug therapy]

\section{MeSH check words}

Adult; Humans

\section{BACKGROUND}

Acute pain occurs as a result of tissue damage either accidentally due to an injury or as a result of surgery. Acute postoperative pain is a manifestation of inflammation due to tissue injury. The management of postoperative pain and inflammation is a critical component of patient care.

This is one of a series of reviews whose aim is to present evidence for relative analgesic efficacy through indirect comparisons with placebo, in very similar trials performed in a standard manner, with very similar outcomes, and over the same duration. Such relative analgesic efficacy does not in itself determine choice of drug for any situation or patient, but guides policy-making at the local level.

Recent reviews include well established analgesics such as paracetamol (Toms 2008), naproxen (Derry C 2009a), diclofenac (Derry P 2009), and ibuprofen (Derry C 2009b), and newer cyclo-oxygenase-2 selective analgesics, such as lumiracoxib (Roy 2007), celecoxib (Derry 2008), etoricoxib (Clarke 2009), and parecoxib (Lloyd 2009).

\section{Acute pain trials}

Single dose trials in acute pain are commonly short in duration, rarely lasting longer than 12 hours. The numbers of participants are small, allowing no reliable conclusions to be drawn about safety. To show that the analgesic is working it is necessary to use placebo (McQuay 2005). There are clear ethical considerations in doing this. These ethical considerations are answered by using acute pain situations where the pain is expected to go away, and by providing additional analgesia, commonly called rescue analgesia, if the pain has not diminished after about an hour. This is reasonable, because not all participants given an analgesic will have significant pain relief. Approximately $18 \%$ of participants given placebo will have significant pain relief (Moore 2006), and up to 50\% may have inadequate 
analgesia with active medicines. The use of additional or rescue analgesia is hence important for all participants in the trials.

Clinical trials measuring the efficacy of analgesics in acute pain have been standardised over many years. Trials have to be randomised and double blind. Typically, in the first few hours or days after an operation, patients develop pain that is moderate to severe in intensity, and will then be given the test analgesic or placebo. Pain is measured using standard pain intensity scales immediately before the intervention, and then using pain intensity and pain relief scales over the following 4 to 6 hours for shorter acting drugs, and up to 12 or 24 hours for longer acting drugs. Pain relief of half the maximum possible pain relief or better (at least 50\% pain relief) is typically regarded as a clinically useful outcome. For patients given rescue medication it is usual for no additional pain measurements to be made, and for all subsequent measures to be recorded as initial pain intensity or baseline (zero) pain relief (baseline observation carried forward). This process ensures that analgesia from the rescue medication is not wrongly ascribed to the test intervention. In some trials the last observation is carried forward, which gives an inflated response for the test intervention compared to placebo, but the effect has been shown to be negligible over 4 to 6 hours (Moore 2005). Patients usually remain in the hospital or clinic for at least the first 6 hours following the intervention, with measurements supervised, although they may then be allowed home to make their own measurements in trials of longer duration.

Knowing the relative efficacy of different analgesic drugs at various doses can be helpful. An example is the relative efficacy in the third molar extraction pain model (Barden 2004).

\section{Dexibuprofen}

This review looks at dexibuprofen. Dexibuprofen is a non-steroidal anti-inflammatory drug (NSAID), sporadically available in different countries, and with no consistent licensed indications. In England in 2006 only 22,000 prescriptions were issued in primary care. This compares with almost eight million prescriptions for naproxen and 4.5 million prescriptions for ibuprofen in the same period (PACT 2007).

Clinicians prescribe NSAIDs on a routine basis for a range of mild to moderate pain. NSAIDs are the most commonly prescribed analgesic medications worldwide, and their efficacy for treating acute pain has been well demonstrated (Moore 2003). They reversibly inhibit cyclooxygenase (prostaglandin endoperoxide synthase), the enzyme mediating production of prostaglandins (PGs) and thromboxane A2 (Fitzgerald 2001). PGs mediate a variety of physiological functions such as maintenance of the gastric mucosal barrier, regulation of renal blood flow, and regulation of endothelial tone. They also play an important role in inflammatory and nociceptive processes. However, relatively little is known about the mechanism of action of this class of compounds aside from their ability to inhibit cyclooxygenase-dependent prostanoid formation (Hawkey 1999).

Dexibuprofen (trade names Deltaran and Seractil) is the single pharmacologically active enantiomer of racemic ibuprofen. Half doses of dexibuprofen are not entirely equivalent to full doses of ibuprofen (Gabard 1995), since there is hepatic conversion of some of the inactive enantiomer to the active form when the racemic mixture is given (Lee 1985). In 
general, the dexibuprofen dose given is half that of ibuprofen, although this may not be the case in some ethnic groups, particularly the Chinese (Zheng 2008). In arthritis, daily doses of $800 \mathrm{mg}$ dexibuprofen produced as much analgesia as $200 \mathrm{mg}$ celecoxib (Hawel 2003), and $1200 \mathrm{mg}$ dexibuprofen as much as $2400 \mathrm{mg}$ ibuprofen (Singer 2000). A review by Phleps 2001 reported clinical efficacy in rheumatoid arthritis, ankylosing spondylitis, osteoarthritis of the hip, osteoarthritis of the knee, lumbar vertebral syndrome, distortion of the ankle joint and dysmenorrhoea.

We could find no systematic review on the efficacy of dexibuprofen in acute pain. This review will look at its efficacy in the setting of acute postoperative pain in adults.

\section{OBJECTIVES}

To assess the efficacy and adverse effects of single dose oral dexibuprofen for acute postoperative pain, using methods that permit comparison with other analgesics evaluated in the same way, using criteria of efficacy recommended by an in-depth study at the individual patient level (Moore 2005).

\section{METHODS}

\section{Criteria for considering studies for this review}

Types of studies-Studies were included if they were double blind trials of single dose oral dexibuprofen compared with placebo for the treatment of moderate to severe postoperative pain in adults with at least 10 participants randomly allocated to each treatment group. Multiple dose studies would be included if appropriate data from the first dose were available. Cross-over studies were included provided that data from the first arm were presented separately. No language restriction was applied to the search for studies.

The following were excluded:

- $\quad$ review articles, case reports, and clinical observations;

- $\quad$ studies of experimental pain;

- $\quad$ studies where pain relief is assessed only by clinicians, nurses or carers (i.e. not patient-reported);

- $\quad$ studies of less than 4 hours duration or studies that fail to present data over 4 to 6 hours post-dose.

For postpartum pain, studies were included if the pain investigated was due to episiotomy or Caesarean section irrespective of the presence of uterine cramps; studies investigating pain due to uterine cramps alone would be excluded.

Types of participants-Studies of adult participants (> $15 \mathrm{yrs}$ ) with established postoperative pain of moderate to severe intensity following day surgery or in-patient surgery would be included. For studies using a visual analogue scale (VAS), pain of at least moderate intensity would be equated to greater than $30 \mathrm{~mm}$ (Collins 1997). 
Types of interventions-Dexibuprofen or matched placebo administered as a single oral dose for postoperative pain.

Types of outcome measures-Data was collected on the following outcomes:

- participant characteristics;

- patient reported pain at baseline (physician, nurse or carer reported pain will not be included in the analysis);

- patient reported pain relief expressed at least hourly over 4 to 6 hours using validated pain scales (pain intensity and pain relief in the form of VAS or categorical scales, or both);

- patient global assessment of efficacy (PGE), using a standard categorical scale;

- time to use of rescue medication;

- number of participants using rescue medication;

- number of participants with one or more adverse events;

- number of participants with serious adverse events;

- number of withdrawals (all cause, adverse event).

\section{Search methods for identification of studies}

To identify studies for inclusion in this review, the following electronic databases were searched:

- Cochrane CENTRAL (issue 2, 2009);

- MEDLINE via Ovid (to May 2009);

- $\quad$ EMBASE via Ovid (to May 2009);

- Oxford Pain Relief Database (Jadad 1996a).

Please see Appendix 1 for the MEDLINE search strategy, Appendix 2 for the EMBASE search strategy, and Appendix 3 for the CENTRAL search strategy.

Additional studies were sought from the reference lists of retrieved articles and reviews.

Language-No language restriction were applied.

Unpublished studies-No manufacturing or distributing pharmaceutical company was contacted for unpublished trial data.

\section{Data collection and analysis}

Selection of studies-Two review authors independently assessed and agreed the search results for studies that might be included in the review. 
Quality assessment-Two review authors independently assessed the included studies for quality using a five-point scale (Jadad 1996b) that considers randomisation, blinding, and study withdrawals and dropouts.

The scale used is as follows.

- Is the study randomised? If yes give one point.

- Is the randomisation procedure reported and is it appropriate? If yes add one point, if no deduct one point.

- Is the study double blind? If yes then add one point.

- Is the double blind method reported and is it appropriate? If yes add one point, if no deduct one point.

- Are the reasons for patient withdrawals and dropouts described? If yes add one point.

Data management-Data was extracted by two review authors and recorded on a standard data extraction form. Data suitable for pooling was entered into RevMan 5.0.

\section{Data analysis}

Number of participants achieving at least $50 \%$ pain relief: For each study, the mean TOTPAR, SPID, VAS TOTPAR or VAS SPID values for active treatment and placebo were converted to \% maxTOTPAR or \%maxSPID by division into the calculated maximum value (Cooper 1991). The proportion of participants in each treatment group who achieved at least 50\%maxTOTPAR was calculated using verified equations (Moore 1996; Moore 1997a;Moore 1997b). These proportions were then converted into the number of participants achieving at least 50\% maxTOTPAR by multiplying by the total number of participants in the treatment group. Information on the number of participants with at least $50 \%$ maxTOTPAR for active treatment and placebo was then used to calculate relative benefit (RB) and number needed to treat to benefit (NNT).

Pain measures accepted for the calculation of TOTPAR or SPID were:

- five-point categorical pain relief (PR) scales with comparable wording to "none, slight, moderate, good or complete";

- four-point categorical pain intensity (PI) scales with comparable wording to "none, mild, moderate, severe";

- Visual analogue scales (VAS) for pain relief;

- VAS for pain intensity.

If none of these measures were available, numbers of participants reporting "very good or excellent" on a five-point categorical global scale with the wording "poor, fair, good, very good, excellent" were taken as those achieving at least 50\% pain relief (Collins 2001).

Further details of the scales and derived outcomes are in the glossary (Appendix 4). 


\section{Secondary outcomes:}

1. Use of rescue medication: Numbers of participants requiring rescue medication were used to calculate relative risk (RR) and numbers needed to treat to prevent (NNTp) use of rescue medication for treatment and placebo groups. Median (or mean) time to use of rescue medication was used to calculate the weighted mean of the median (or mean) for the outcome. Weighting was planned to be by number of participants.

2. Adverse events: Numbers of participants reporting adverse events for each treatment group were used to calculate $\mathrm{RR}$ and numbers needed to treat to harm (NNH) estimates for:

i. any adverse event,

ii. any serious adverse event (as reported in the study),

iii. withdrawal due to an adverse event.

3. Withdrawals: Withdrawals for reasons other than lack of efficacy (participants using rescue medication - see above) and adverse events were noted, as were exclusions from analysis where data were presented.

RB or RR estimates were calculated with $95 \%$ confidence intervals (CI) using a fixed-effect model (Morris 1995). NNT, NNTp and NNH with 95\% CIs were calculated using the pooled number of events by the method of Cook and Sackett (Cook 1995). A statistically significant difference from control was assumed when the 95\% CI of the RB did not include the number one. Homogeneity of studies was assessed visually (L'Abbé 1987).

\section{RESULTS}

\section{Description of studies}

See: Characteristics of included studies; Characteristics of excluded studies.

Searches identified two potentially relevant studies (Dionne 1998;Jamali 1999). Only one study (176 participants; 101 receiving dexibuprofen) satisfied criteria for inclusion in this review (Dionne 1998). The other was a pharmacokinetic study without pain measures (Jamali 1999). Details of these studies are in the 'Characteristics of included studies' and 'Characteristics of excluded studies' tables.

\section{Risk of bias in included studies}

The included study had an Oxford quality score of four points, minimising risk of bias.

\section{Effects of interventions}

In the included study, both $\mathrm{S}(+$ )-ibuprofen (dexibuprofen) $200 \mathrm{mg}$ and $400 \mathrm{mg}$ gave high levels of response, with $31 / 51(61 \%)$ and $35 / 50(70 \%)$ respectively having at least $50 \%$ pain relief over 4 to 6 hours, compared with $2 / 25$ (8\%) with placebo. The median time to additional analgesic use was 5.8 hours, 6.1 hours, and 1.8 hours respectively. The numbers of participants was too small to calculate NNTs with any meaning. 


\section{DISCUSSION}

Dexibuprofen is not a widely available NSAID, and there is no large literature describing its use in clinical pain conditions, though a review by Phleps 2001 clinical efficacy of dexibuprofen was reported in rheumatoid arthritis, ankylosing spondylitis, osteoarthritis of the hip, osteoarthritis of the knee, lumbar vertebral syndrome, distortion of the ankle joint and dysmenorrhoea. The information from the single trial in acute postoperative pain suggests it to be a useful analgesic, but at doses not very different from racemic ibuprofen.

\section{AUTHORS' CONCLUSIONS}

Implications for practice

There are no implications for practice because there is insufficient information, at present, to draw conclusions.

\section{Implications for research}

A considerable additional body of clinical trial results are needed to know whether dexibuprofen has any advantages in efficacy, or faster analgesic onset, or safety over racemic ibuprofen.

\section{Acknowledgments}

\section{SOURCES OF SUPPORT}

Internal sources

- Oxford Pain Research Funds, UK.

External sources

- $\quad$ NHS Cochrane Collaboration Grant, UK.

- $\quad$ NIHR Biomedical Research Centre Programme, UK.

RAM Funding

\section{Appendix 1. MEDLINE search strategy (via OVID)}

1 Dexibuprofen/ (0)2 (dexibuprofen or ((S or +) adj6 ibuprofen)).mp. (336)

3 (deltaran or seractil).mp. (18)

41 or 3 or $2(349)$

5 Pain, Postoperative/ (19481)

6 ((postoperative adj4 pain*) or (post-operative adj4 pain*) or post-operative-pain* or (post* adj4 pain*) or (postoperative adj4 analgesi*) or (post-operative adj4 analgesi*) or "postoperative analgesi*”).mp. (32630)

7 ((post-surgical adj4 pain*) or (“post surgical” adj4 pain*) or (post-surgery adj4 pain*)).mp. (182) 
8 ("pain-relief after surg*" or "pain following surg*" or "pain control after").mp. (385)

9 (("post surg*" or post-surg*) and (pain* or discomfort)).mp. (682)

10 ((pain* adj4 “after surg*”) or (pain* adj4 "after operat*”) or (pain* adj4 "follow* operat*”) or (pain* adj4 “follow* surg*”)).mp. (1831)

11 ((analgesi* adj4 “after surg*”) or (analgesi* adj4 “after operat*”) or (analgesi* adj4 "follow* operat*") or (analgesi* adj4 "follow* surg*")).mp. (426)

12 or/5-11 (34021)

13 exp Surgical Procedures, Operative/ (1812522)

1412 or $13(1826452)$

15 randomized controlled trial.pt. (269889)

16 controlled clinical trial.pt. (79129)

17 randomized.ab. (190830)

18 placebo.ab. (116206)

19 drug therapy.fs. (1302339)

20 randomly.ab. (141193)

21 trial.ab. (198055)

22 groups.ab. (956958)

23 or/15-22 (2456370)

24 humans.sh. (10663713)

2523 and 24 (1939160)

2625 and 14 (250563)

274 and 26 (7)

\section{Appendix 2. Search strategy for EMBASE (via Ovid)}

EMBASE <1980 to 2009 Week 17>

1 Dexibuprofen/ (88)2 (dexibuprofen or ((S or +) adj6 ibuprofen)).mp. (440)

3 (deltaran or seractil).mp. (30)

41 or 3 or $2(440)$ 
5 Pain, Postoperative/ (19611)

6 ((postoperative adj4 pain*) or (post-operative adj4 pain*) or post-operative-pain* or (post* adj4 pain*) or (postoperative adj4 analgesi*) or (post-operative adj4 analgesi*) or "postoperative analgesi*").mp. (37987)

7 ((post-surgical adj4 pain*) or ("post surgical" adj4 pain*) or (post-surgery adj4 pain*)).mp. (204)

8 ("pain-relief after surg*" or "pain following surg*” or "pain control after").mp.(333)

9 ((“post surg*” or post-surg*) and (pain* or discomfort)).mp.(671)

10 ((pain* adj4 “after surg*”) or (pain* adj4 "after operat*”) or (pain* adj4 "follow* operat*”) or (pain* adj4 “follow* surg*”)).mp. (1588)

11 ((analgesi* adj4 "after surg*”) or (analgesi* adj4 "after operat*”) or (analgesi* adj4 "follow* operat*”) or (analgesi* adj4 "follow* surg*”)).mp. (391)

12 or/5-11 (39075)

13 exp Surgical Procedures, Operative/ (1512019)

1412 or $13(1521438)$

15 random*.ti,ab. (396274)

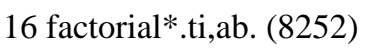

17 (crossover* or cross over* or cross-over*).ti,ab. (39585)

18 placebo*.ti,ab. (110475)

19 (doubl* adj blind*).ti,ab. (85078)

20 (singl* adj blind*).ti,ab. (7497)

21 assign*.ti,ab. (109080)

22 allocat*.ti,ab. (34524)

23 volunteer*.ti,ab. (99462)

24 CROSSOVER PROCEDURE.sh. (21239)

25 DOUBLE-BLIND PROCEDURE.sh. (72216)

26 RANDOMIZED CONTROLLED TRIAL.sh. (168246)

27 SINGLE BLIND PROCEDURE.sh. (8128)

28 or/15-27 (663334) 
29 ANIMAL/ or NONHUMAN/ or ANIMAL EXPERIMENT/ (3450348)

30 HUMAN/ (6469375)

3129 and 30 (538433)

3229 not $31(2911915)$

$3328 \operatorname{not} 32(577725)$

3414 and $33(95996)$

3534 and $4(4)$

\section{Appendix 3. Search strategy for Cochrane CENTRAL}

1. (dexibuprofen OR Deltaran or Seractil)):ti,ab,kw.

2. MESH descriptor Pain, Postoperative.

3. ((postoperative adj4 pain\$) or (post-operative adj4 pain\$) or post-operative-pain\$ or (post\$ NEAR pain\$) or (postoperative adj4 analgesi\$) or (post-operative adj4 analgesi\$) or (“post-operative analgesi\$”)):ti,ab,kw.

4. ((post-surgical adj4 pain\$) or (“post surgical” adj4 pain\$) or (post-surgery adj4 pain\$)):ti,ab,kw.

5. (("pain-relief after surg\$”) or ("pain following surg\$”) or ("pain control after")):ti,ab,kw.

6. ((“post surg\$” or post-surg\$) AND (pain\$ or discomfort)):ti,ab,kw.

7. ((pain\$ adj4 “after surg\$”) or (pain\$ adj4 "after operat\$”) or (pain\$ adj4 “follow\$ operat\$”) or (pain\$ adj4 “follow\$ surg\$”)): ti,ab,kw.

8. ((analgesi $\$$ adj4 “after surg\$”) or (analgesi\$ adj4 “after operat\$”) or (analgesi $\$$ adj4 "follow\$ operat\$”) or (analgesi\$ adj4 “follow\$ surg\$”)):ti,ab,kw.

9. $\mathrm{OR} / 2-8$

10. Clinical trial:pt.

11. Controlled Clinical Trial:pt.

12. Randomized Controlled Trial:pt.

13. MeSH descriptor Double-Blind Method

14. (clin\$ adj25 trial\$):ti,ab,kw.

15. ((doubl\$ or trebl\$ or tripl\$) adj25 (blind\$ or mask\$)):ti,ab,kw.

16. placebo $\$: \mathrm{ti}, \mathrm{ab}, \mathrm{kw}$.

17. random $\$: \mathrm{ti}, \mathrm{ab}, \mathrm{kw}$.

18. $\mathrm{OR} / 10-17$ 
19. 1 AND 9 AND 18

\section{Appendix 4. Glossary \\ Categorical rating scale}

The commonest is the five category scale (none, slight, moderate, good or lots, and complete). For analysis numbers are given to the verbal categories (for pain intensity, none $=0$, mild $=1$, moderate $=2$ and severe $=3$, and for relief none $=0$, slight $=1$, moderate $=2$, good or lots $=3$ and complete $=4$ ). Data from different subjects is then combined to produce means (rarely medians) and measures of dispersion (usually standard errors of means). The validity of converting categories into numerical scores was checked by comparison with concurrent visual analogue scale measurements. Good correlation was found, especially between pain relief scales using cross-modality matching techniques. Results are usually reported as continuous data, mean or median pain relief or intensity. Few studies present results as discrete data, giving the number of participants who report a certain level of pain intensity or relief at any given assessment point. The main advantages of the categorical scales are that they are quick and simple. The small number of descriptors may force the scorer to choose a particular category when none describes the pain satisfactorily.

VAS

Visual analogue scale: lines with left end labelled "no relief of pain" and right end labelled "complete relief of pain", seem to overcome this limitation. Patients mark the line at the point which corresponds to their pain. The scores are obtained by measuring the distance between the no relief end and the patient's mark, usually in millimetres. The main advantages of VAS are that they are simple and quick to score, avoid imprecise descriptive terms and provide many points from which to choose. More concentration and coordination are needed, which can be difficult post-operatively or with neurological disorders.

\section{TOTPAR}

Total pain relief (TOTPAR) is calculated as the sum of pain relief scores over a period of time. If a patient had complete pain relief immediately after taking an analgesic, and maintained that level of pain relief for six hours, they would have a six-hour TOTPAR of the maximum of 24. Differences between pain relief values at the start and end of a measurement period are dealt with by the composite trapezoidal rule. This is a simple method that approximately calculates the definite integral of the area under the pain relief curve by calculating the sum of the areas of several trapezoids that together closely approximate to the area under the curve.

\section{SPID}

Summed pain intensity difference (SPID) is calculated as the sum of the differences between the pain scores over a period of time. Differences between pain intensity values at the start and end of a measurement period are dealt with by the trapezoidal rule. 
VAS TOTPAR and VAS SPID are visual analogue versions of TOTPAR and SPID.

See "Measuring pain" in Bandolier's Little Book of Pain, Oxford University Press, Oxford. 2003; pp 7-13 (Moore 2003).

\section{CHARACTERISTICS OF STUDIES}

\section{Characteristics of included studies [ordered by study ID]}

Dionne 1998

\begin{tabular}{|c|c|}
\hline Methods & $\begin{array}{l}\text { RCT, DB, single oral dose, } 4 \text { parallel groups } \\
\text { Medication administered when baseline pain was of moderate to severe intensity } \\
\text { Pain assessed at } 0,15,30,45,60 \text { mins, then hourly up to } 6 \text { hours }\end{array}$ \\
\hline Participants & $\begin{array}{l}\text { Third molar extraction } \\
\mathrm{N}=181(176 \text { analysed for efficacy) } \\
\mathrm{M}=50, \mathrm{~F}=126 \\
\text { Mean age } 22 \text { years }\end{array}$ \\
\hline Interventions & $\begin{array}{l}\mathrm{S}(+) \text {-Ibuprofen (dexibuprofen) } 200 \mathrm{mg}, \mathrm{n}=51 \\
\mathrm{~S}(+) \text {-Ibuprofen (dexibuprofen) } 400 \mathrm{mg}, \mathrm{n}=50 \\
\text { Ibuprofen (racemic) } 400 \mathrm{mg}, \mathrm{n}=50 \\
\text { Placebo, } \mathrm{n}=25\end{array}$ \\
\hline Outcomes & $\begin{array}{l}\text { PI: std } 4 \text { point scale and } 100 \mathrm{~mm} \text { VAS } \\
\text { PR: std } 5 \text { point scale and } 100 \mathrm{~mm} \text { VAS } \\
\text { Time to use of rescue medication } \\
\text { Withdrawals }\end{array}$ \\
\hline Notes & $\begin{array}{l}\text { Oxford Quality Score: R1, DB2, W1 } \\
\text { Rescue medication permitted - no further details }\end{array}$ \\
\hline
\end{tabular}

\section{Characteristics of excluded studies [ordered by study ID]}

\begin{tabular}{ll}
\hline Study & Reason for exclusion \\
\hline Jamali 1999 & $\begin{array}{l}\text { Fewer than } 10 \text { per group } \\
\text { Pharmacokinetic study - no pain measures }\end{array}$ \\
\hline
\end{tabular}

\section{DATA AND ANALYSES}

This review has no analyses.

\section{HISTORY}

Protocol first published: Issue 1, 2009

Review first published: Issue 3, 2009

\begin{tabular}{lll}
\hline Date & Event & Description \\
\hline 24 September 2010 & Amended & Contact details updated. \\
\hline
\end{tabular}




\section{DIFFERENCES BETWEEN PROTOCOL AND REVIEW}

There are no differences between the protocol and the review.

\section{WHAT'S NEW}

Last assessed as up-to-date: 9 November 2010.

\begin{tabular}{lll}
\hline Date & Event & Description \\
\hline 10 November 2010 & $\begin{array}{l}\text { Review declared as } \\
\text { stable }\end{array}$ & $\begin{array}{l}\text { The authors declare that there is unlikely to be any further studies to be } \\
\text { included in this review and so it should be published as a 'stable review' }\end{array}$ \\
\hline
\end{tabular}

\section{References to studies included in this review}

Dionne 1998 \{published data only\} . Dionne RA, McCullagh L. Enhanced analgesia and suppression of plasma B-endorphin by the $\mathrm{S}(+)$-isomer of ibuprofen. Clinical Pharmacology and Therapeutics. 1998; 63(5):694-701. [PubMed: 9663185]

\section{References to studies excluded from this review}

Jamali 1999 \{published data only . Jamali F, Kunz-Dober CM. Pain-mediated altered absorption and metabolism of ibuprofen: an explanation for decreased serum enantiomer concentration after dental surgery. British Journal of Clinical Pharmacology. 1999; 47(4):391-6. [PubMed: 10233203]

\section{Additional references}

Barden 2004 . Barden J, Edwards JE, McQuay HJ, Wiffen PJ. Relative efficacy of oral analgesics after third molar extraction. British Dental Journal. 2004; 197(7):407-11. [PubMed: 15475903]

Clarke 2009 . Clarke R, Derry S, Moore RA, McQuay HJ. Single dose oral etoricoxib for acute postoperative pain in adults. Cochrane Database of Systematic Reviews. 2009; (Issue 2) [DOI: 10.1002/14651858.CD004309].

Collins 1997 . Collins SL, Moore RA, McQuay HJ. The visual analogue pain intensity scale: what is moderate pain in millimetres? Pain. 1997; 72:95-7. [PubMed: 9272792]

Collins 2001 . Collins SL, Edwards J, Moore RA, Smith LA, McQuay HJ. Seeking a simple measure of analgesia for mega-trials: is a single global assessment good enough? Pain. 2001; 91(1-2): 189-94. [PubMed: 11240091]

Cook 1995 . Cook RJ, Sackett DL. The number needed to treat: a clinically useful measure of treatment effect. BMJ. 1995; 310(6977):452-4. [PubMed: 7873954]

Cooper 1991 . Cooper SA. Single-dose analgesic studies: the upside and downside of assay sensitivity. The Design of Analgesic Clinical Trials. Advances in Pain Research Therapy. 1991; 18:117-24.

Derry 2008 . Derry S, Moore RA, McQuay HJ. Single dose oral celecoxib for acute postoperative pain. Cochrane Database of Systematic Reviews. 2008; (Issue 4) [DOI: 10.1002/14651858.CD004233].

Derry C 2009a . Derry C, Derry S, Moore RA, McQuay HJ. Single dose oral naproxen and naproxen sodium for acute postoperative pain in adults. Cochrane Database of Systematic Reviews. 2009; (Issue 1) [DOI: 10.1002/14651858.CD004234.pub2].

Derry C 2009b . Derry C, Derry S, Moore RA, McQuay HJ. Single dose oral ibuprofen for acute postoperative pain in adults. Cochrane Database of Systematic Reviews. 2009 
Derry P 2009 . Derry P, Derry S, Moore RA, McQuay HJ. Single dose oral diclofenac for acute postoperative pain in adults. Cochrane Database of Systematic Reviews. 2009; (Issue 2) [DOI: 10.1002/14651858.CD004768].

Fitzgerald 2001 . FitzGerald GA, Patrono C. The coxibs, selective inhibitors of cyclooxygenase-2. New England Journal of Medicine. 2001; 345(6):433-42. [PubMed: 11496855]

Gabard 1995 . Gabard B, Nirnberger G, Schiel H, Mascher H, Kikuta C, Mayer JM. Comparison of the bioavailability of dexibuprofen administered alone or as part of racemic ibuprofen. European Journal of Clinical Pharmacology. 1995; 48(6):505-11. [PubMed: 8582471]

Hawel 2003 . Hawel R, Klein G, Singer F, Mayrhofer F, Kahler ST. Comparison of the efficacy and tolerability of dexibuprofen and celecoxib in the treatment of osteoarthritis of the hip. International journal of Clinical Pharmacology and Therapeutics. 2003; 41(4):153-64. [PubMed: 12708604]

Hawkey 1999 . Hawkey CJ. Cox-2 inhibitors. Lancet. 1999; 353(9149):307-14. [PubMed: 9929039]

Jadad 1996a . Jadad AR, Carroll D, Moore RA, McQuay H. Developing a database of published reports of randomised clinical trials in pain research. Pain. 1996; 66(2-3):239-46. [PubMed: 8880846]

Jadad 1996b . Jadad AR, Moore RA, Carroll D, Jenkinson C, Reynolds DJM, Gavaghan DJ, et al. Assessing the quality of reports of randomized clinical trials: is blinding necessary? Controlled Clinical Trials. 1996; 17:1-12. [PubMed: 8721797]

L’Abbé 1987 . L’Abbé KA, Detsky AS, O'Rourke K. Meta-analysis in clinical research. Annals of Internal Medicine. 1987; 107:224-33. [PubMed: 3300460]

Lee 1985 . Lee EJ, Williams K, Day R, Graham G, Champion D. Stereoselective disposition of ibuprofen enantiomers in man. British Journal of Clinical Pharmacology. 1985; 19(5):669-74. [DOI: 10.1111/j.1365-2125.2004.02288.x]. [PubMed: 4005104]

Lloyd 2009 . Lloyd R, Derry S, Moore RA, McQuay HJ. Intravenous parecoxib for acute postoperative pain in adults. Cochrane Database of Systematic Reviews. 2009; (Issue 2) [DOI: 10.1002/14651858.CD004771.pub4].

McQuay 2005 . McQuay HJ, Moore RA. Placebo. Postgraduate Medical Journal. 2005; 81:155-60. [PubMed: 15749790]

Moore 1996 . Moore A, McQuay H, Gavaghan D. Deriving dichotomous outcome measures from continuous data in randomised controlled trials of analgesics. Pain. 1996; 66(2-3):229-37. [DOI: 10.1016/0304-3959(96)03032-1]. [PubMed: 8880845]

Moore 1997a . Moore A, Moore O, McQuay H, Gavaghan D. Deriving dichotomous outcome measures from continuous data in randomised controlled trials of analgesics: use of pain intensity and visual analogue scales. Pain. 1997; 69(3):311-5. [DOI: 10.1016/S0304-3959(96)03306-4]. [PubMed: 9085306]

Moore 1997b . Moore A, McQuay H, Gavaghan D. Deriving dichotomous outcome measures from continuous data in randomised controlled trials of analgesics: verification from independent data. Pain. 1997; 69(1-2):127-30. [DOI: 10.1016/S0304-3959(96)03251-4]. [PubMed: 9060022]

Moore 2003 . Moore, RA.; Edwards, J.; Barden, J.; McQuay, HJ. Bandolier's Little Book of Pain. Oxford University Press; Oxford: 2003. [ISBN: 0-19-263247-7]

Moore 2005 . Moore RA, Edwards JE, McQuay HJ. Acute pain: individual patient meta-analysis shows the impact of different ways of analysing and presenting results. Pain. 2005; 116(3):32231. [DOI: 10.1016/j.pain.2005.05.001]. [PubMed: 15979792]

Moore 2006 . Moore, A.; McQuay, H. Bandolier's Little Book of Making Sense of the Medical Evidence. Oxford University Press; Oxford: 2006. [ISBN: 0-19-856604-2]

Morris 1995 . Morris, JA.; Gardner, MJ. Calculating confidence intervals for relative risk, odds ratio and standardised ratios and rates. In: Gardner, MJ.; Altman, DG., editors. Statistics with Confidence - Confidence Intervals and Statistical Guidelines. British Medical Journal; London: 1995. p. 50-63.

PACT 2007 . Prescription Cost Analysis. England: 2007. [ISBN: 978-1-84636-210-1]

Phleps 2001 . Phleps W. Overview on clinical data of dexibuprofen. Clinical Rheumatology. 2001; 20(Suppl 1):S15-2. [PubMed: 11771569] 
Roy 2007 . Roy YM, Derry S, Moore RA. Single dose oral lumiracoxib for postoperative pain.

Cochrane Database of Systematic Reviews. 2007; (Issue 4) [DOI: 10.1002/14651858.CD006865].

Singer 2000 . Singer F, Mayrhofer F, Klein G, Hawel R, Kollenz CJ. Evaluation of the efficacy and dose-response relationship of dexibuprofen ( $\mathrm{S}(+)$-ibuprofen) in patients with osteoarthritis of the hip and comparison with racemic ibuprofen using the WOMAC osteoarthritis index. International Journal of Clinical Pharmacology and Therapeutics. 2000; 38(1):15-24. [PubMed: 10667832]

Toms 2008 . Toms L, McQuay HJ, Derry S, Moore RA. Single dose oral paracetamol (acetaminophen) for postoperative pain in adults. Cochrane Database of Systematic Reviews. 2008; (Issue 4) [DOI: 10.1002/14651858.CD004602].

Zheng 2008 . Zheng C, Hao H, Wang G, Sang G, Sun J, Li P, et al. Chiral separation of ibuprofen and chiral pharmacokinetics in healthy Chinese volunteers. European Journal of Drug Metabolism and Pharmacokinetics. 2008; 33(1):45-51. [PubMed: 18543584]

* Indicates the major publication for the study 


\section{PLAIN LANGUAGE SUMMARY}

\section{Single dose oral dexibuprofen for acute postoperative pain in adults}

Pain is commonly experienced after surgical procedures. Acute postoperative pain of moderate or severe intensity is often used (as a model) to test whether or not drugs are effective painkillers. In this case a single study tested dexibuprofen against placebo and found it to provide useful pain relief, but the small numbers of trials and participants means that no reliance can be placed on the results. 